\title{
Hablando de pandemias y pared vascular. Desde el endotelio hacia lo socioeconómico-psicológico: una aproximación con evidencia
}

Enrique Melgarejo $R^{* 1, a, b}$

\section{RESUMEN}

En este artículo se hace una somera revisión de las pandemias sufridas por la humanidad a través de la historia y, además, un análisis de la presente pandemia, producida por un "extraño" virus que ha generado una enfermedad nueva y compleja. De ella, describimos su “nueva” fisiopatología centrada en la pared vascular (y, más concretamente, en el endotelio) y planteamos la posibilidad de detectar una disfunción endotelial subclínica en pacientes jóvenes, quienes han demostrado susceptibilidad y letalidad diferentes. Finalmente, se trata de contestar la pregunta: ¿esta pandemia nos cambiará o ayudará a cambiarnos?

Palabras clave: Pandemias; COVID-19; SARS-CoV-2; Endotelio (Fuente: DeCS BIREME).

\section{Speaking of pandemics and vascular walls. From the endothelium to socioeconomic-psychological aspects: an evidence-based approach}

\section{ABSTRACT}

This article briefly reviews the pandemics suffered by humankind throughout its history. Additionally, it analyzes the current pandemic caused by a "strange" virus that has generated a new and complex disease. A description of its "new" vascular wall-centered physiopathology (and more specifically from the endothelium) is given. Moreover, the possibility to detect a subclinical endothelial dysfunction in young patients who have shown different susceptibility and lethality indices is considered. Finally, the question “will this pandemic change us or will it help us change?" is attempted to be answered.

Keywords: Pandemics; Coronavirus infections; SARS-CoV-2; Endothelium (Source: MeSH NLM).

1 Universidad Militar Nueva Granada. Bogotá, Colombia.

a Profesor Emérito Hospital Militar Central.

b Expresidente Sociedad Colombiana de Cardiología y Cirugía Cardiovascular.

*Autor corresponsal. 


\section{INTRODUCCIÓN}

\section{¡Paren el mundo que me quiero bajar! Mafalda}

$Y$ nosotros mismos paramos al mundo por culpa de un "raro" virus, pero, por fenómenos gravitacionales, no nos pudimos bajar del planeta sino, simple y duramente, tan solo recurrimos a la confinación (o, mejor dicho, nos confinaron) y a la ruptura de tradiciones de contacto social y manifestaciones cercanas de afecto.

Este virus tuvo una expansión rápida como ningún otro coronavirus u otro virus. Fue obvio que nos tomó por sorpresa y ha causado angustia, incertidumbre, miedos, depresión, colapso económico y hasta crisis; y mortalidad inusitada, incluso en los sistemas de salud, y saturación de las unidades de cuidados intensivos en algunas regiones. Ha generado un nuevo aprendizaje acerca de cómo ver las pandemias y sus complicaciones: desde el punto de vista molecular y de plausibilidad ante lo desconocido.

\section{ESTRATEGIA DE BÚSQUEDA}

Para la presente revisión se realizó una búsqueda en bases de datos bibliográficas como Pubmed, CINAHL, SciELO, LILACS, PubMed, Medscape, The Heart.Org, www.who.int, App COVID-19! y Google académico, entre estudios primarios, revisiones, consensos y guías clínicas, desde 1990 hasta el 1 de noviembre de 2019, en los idiomas inglés y español. Los términos de búsqueda utilizados fueron los siguientes: pandemias, coronavirus, COVID-10, SARS-CoV-2 y endotelitis.

\section{El inicio del problema}

En diciembre de 2019, la ciudad de Wuhan, capital regional de la provincia de Hubei, se convirtió en el epicentro de un brote de neumonía de causa desconocida ${ }^{(1)}$.

En diferentes hospitales de Hubei ingresaron pacientes con diagnóstico de neumonía de etiología no conocida. La mayoría de ellos estaban relacionados, epidemiológicamente, con un "mercado húmedo" mayorista de pescados, mariscos y animales vivos no procesados ${ }^{(2,3)}$.

Los primeros cinco casos fueron reportados entre el 18 y el 29 de diciembre del 2019. De ellos, cuatro fueron hospitalizados por presentar un síndrome de distrés respiratorio agudo, y uno de estos pacientes falleció (4).

En los días siguientes, el número de personas contagiadas fue aumentando exponencialmente en China continental, y para el 30 de enero se habían reportado 9692 casos en toda China y 90 casos en diferentes lugares como Taiwán, Tailandia, Vietnam, Malasia, Nepal, Sri Lanka, Camboya,
Japón, Singapur, la República de Corea, Emiratos Árabes Unidos, Estados Unidos, Filipinas, India, Irán, Australia, Canadá, Finlandia, Italia, Francia y Alemania ${ }^{(5,6)}$.

El primer caso en América se registró el 19 de enero de 2020 en el estado de Washington (EE. UU.). El paciente fue un hombre de 35 años de edad que presentó tos, disnea y fiebre, y que había estado en Wuhan, China ${ }^{(7)}$. En Europa, el primer caso de COVID-19 apareció el 24 de enero de 2020, en Burdeos (Francia), y corresponde a un paciente de 48 años de edad procedente de China ${ }^{(8)}$.

El miércoles 26 de febrero, el Ministerio de Salud de Brasil confirmó el primer caso de COVID-19 en Sudamérica. Se trató de un hombre de 61 años de Sao Paulo que, recientemente, había viajado por negocios a Lombardía (Italia), y presentó síntomas leves de esta infección y fue puesto en cuarentena ${ }^{(9)}$.

\section{LOS CORONAVIRUS}

Al inicio, y de manera temporal, el virus fue denominado 2019 Novel Coronavirus (2019-nCoV) por las diferencias que existan entre este nuevo coronavirus y los que ya son conocidos ${ }^{\left({ }^{10}\right)}$. Hasta el momento, se sabe que, en total, existen 36 coronavirus que pertenecen a la familia Coronaviridae. Son virus de tipo ARN positivo de cadena simple, están envueltos por una cápside y pueden infectar a un amplio rango de animales y también a los humanos. Fueron descritos por primera vez por Tyrrell y Bynoe en $1965^{(11)}$.

Los coronavirus son una extensa familia viral con una antigüedad mayor de 10000 años y han sido prevalentes en otras especies. Están clasificados en cuatro subfamilias: alfa, beta, gamma y deltacoronavirus. Aparentemente, los virus alfa y beta se originan de mamíferos como murciélagos; y los gamma y delta, de cerdos y aves. Los betacoronavirus son los más letales ${ }^{(12)}$.

Diversos coronavirus causan infecciones respiratorias en los humanos. Estos cuadros pueden ser resfriados comunes o enfermedades más graves como el síndrome respiratorio de Oriente Medio (MERS, del inglés Middle East Respiratory Syndrome) o el síndrome respiratorio agudo y grave (SARS, por sus siglas en inglés Severe Acute Respiratory Syndrome). Existen siete tipos de coronavirus que pueden infectar al hombre ${ }^{(13)}$, entre ellos los denominados HcoV-229E, HCoVNL63, HCoVHKU1 y HcoV-OC43 que suelen ocasionar el resfriado común y que en personas inmunosuprimidas pueden ser, potencialmente, más graves. Los demás virus que han causado brotes de enfermedades graves en humanos son el SARS- CoV (2002-2003), MERS CoV (2012-actualidad) y el SARS-CoV-2 (de 2019 hasta hoy), del cual se desconoce hasta cuándo permanecerá. En el 2003, el SARS fue mucho más letal, con una tasa de mortalidad de $10 \%$, pero con 8000 casos y 774 muertes ${ }^{(13)}$. 
Hablando de pandemias y pared vascular. Desde el endotelio hacia lo

socioeconómico-psicológico: una aproximación con evidencia

Según diferentes informes de la OMS (Organización Mundial de la Salud), el SARS-CoV-2 tiene una letalidad relativamente baja y variable en las distintas regiones (entre 0,8-14\%), pero su velocidad de propagación es exagerada, tanto que, en menos de 3 meses, pasó de ser un brote o epidemia a una pandemia.

\section{HISTORIA DE LAS PANDEMIAS Y LAS PANDEMIAS EN LA HISTORIA}

\section{Las pandemias nos acercan a la incertidumbre}

En esta primera quinta parte del siglo XXI nos hemos enfrentado a epidemias y pandemias ocasionadas por distintos tipos de virus (SARS, MERS, COVID-19, H1N1) y a otras enfermedades virales tales como el ébola, zika, chikunguña y el dengue, además del VIH (virus de la inmunodeficiencia humana) ya establecido desde 1983, pero en expansión progresiva.

Con respecto al SARS, la "neumonía asiática" apareció a mediados de noviembre de 2002. La epidemia comenzó en Guangdong (sur de China). A fines de febrero del 2003, la enfermedad se difundió rápidamente a Hong Kong, Vietnam, Singapur y Canadá debido a que un nefrólogo chino proveniente de Guangdong viajó a Hong Kong por negocios y contagió a varias personas en un hotel. En un primer momento, los trabajadores de salud fueron los más afectados, ya que atendieron a los enfermos antes de que esta nueva enfermedad se conociera y las medidas de aislamiento necesarias fueran aplicadas. A mediados de marzo, la OMS emite una alerta mundial acerca de esta enfermedad altamente transmisible y cuya etiología era desconocida, hasta que pudo identificarse como una variante de coronavirus ${ }^{(12)}$. Se infirió que provenía de los hurones que consumen los chinos y que "saltó" al hombre.

En 2009, en México fue reportada una nueva enfermedad que la OMS declaró pandemia. Este cuadro fue causado por el virus de influenza H1N1 (llamado influenza porcina, al inicio) y podía transmitirse de persona a persona. En pocos meses la enfermedad se había diagnosticado en muchos países, pero su letalidad no fue tan alta. En Alemania, en el 2011, empezó el brote de una infección en el ganado bovino que fue bautizada como enfermedad de Schalmallenberg y cuya etiología corresponde a un virus transmitido por vectores clasificados dentro de la familia Bunyaviridae. La epidemia se diseminó por varios países de Europa, pero no se transmitió a los humanos, aunque sí ocasionó pérdidas económicas por su efecto sobre la reproducción del ganado y en las barreras del comercio internacional. En 2013, se inició un brote de una enfermedad respiratoria en la ciudad de Shanghái. El agente responsable se identificó como una nueva variante del virus de influenza aviar HTN, y el 9 de mayo del mismo año 31 personas habían fallecido, de un total de 129 contagiados con la nueva dolencia (12). Las epidemias y pandemias aparecen desde las épocas bíblicas del Antiguo Testamento. Debemos aclarar que en tiempos antiguos cualquier enfermedad que afectara una región en un mundo aún desconocido reunía los criterios para describirla hoy como pandemia. En el año 429 a. de C., durante la guerra del Peloponeso (siglo de Pericles), el historiador Tucídides describe una pandemia que azotó a ambos ejércitos y contribuyó enormemente al desenlace de la guerra. Asimismo, en el imperio bizantino apareció la peste de Justiniano -quien la padeció y se salvó-, que provocó la muerte de alrededor de 4 millones de personas.

\section{De la muerte negra al renacimiento}

Las epidemias siempre han existido y han impactado en la historia, pero, sin duda, la que marcó a la humanidad fue la pandemia que asoló Asia y Europa en el siglo XIV, llamada peste negra o peste bubónica (peste por la pestilencia que generaba, bubónica por los bubones o crecimiento ganglionar, y negra por la necrosis y trombosis que originaba). Esta enfermedad mató a casi la mitad de la población de Europa de esa época, causó un gran sufrimiento y cambió el mundo como pocos acontecimientos lo han hecho nunca. Puso fin a la cultura medieval y dio luz a la cultura renacentista y moderna; además, generó sentimientos de culpa ante Dios, soledad y sufrimiento; e hizo que el hombre adquiriese una nueva perspectiva de ver y afrontar tanto la vida como la muerte.

La peste negra se originó en la ciudad de Caffa (Crimea) durante la invasión de los mongoles. Estos guerreros catapultaban sus cadáveres infectados por encima de las murallas (primera guerra biológica). El pueblo entero empezó a migrar y así la enfermedad llegó a Europa: al primer lugar que arribó fue Italia, que también era parte de la ruta de la seda en ese momento. Los enfermos y muertos eran abandonados por sus familiares; y la peste se propagó durante trece años por todo el continente (1346-1350). El vector de la peste era la pulga y el reservorio, las ratas. En esa época los gérmenes viajaban a la velocidad del galope de caballo (como máximo, a $50 \mathrm{~km} / \mathrm{h}$ y por $200 \mathrm{~km}$ cada día) a través de las estepas o en barcos. Ahora los virus viajan a 890 o $1040 \mathrm{~km} / \mathrm{h}$ en aviones comerciales y hasta un trayecto de $15000 \mathrm{~km}$ en un vuelo internacional. Casi cinco siglos después, los bacteriólogos Kitasato y Yersin descubrieron la bacteria causante de la peste bubónica, posteriormente denominada Yersinia pestis. Al inicio, los judíos fueron culpados por la enfermedad porque casi no se enfermaban y por ello, muchos fueron condenados a muerte. La razón era que efectuaban sus abluciones antes de tomar los alimentos y de entrar a las sinagogas: en esa época no se conocía la higiene. Bocaccio, en el Decamerón, compila relatos escalofriantes de esta epidemia-pandemia. Fue tal la mortalidad que la humanidad, por vez primera, descubrió o le tocó vivir la soledad y el duelo (antes de las guerras mundiales). Las ciudades, vistas como auténticos campos de muerte, eran sinónimo de podredumbre, cadáveres, suciedad, malos olores, tristeza, desolación, llanto, miedo 
y dudas o temor a Dios, y quedaron abandonadas debido al éxodo masivo al campo, lugar en el que estos sentimientos eran menos comunes, a pesar de que también se sufría por la epidemia.

Debido a la gran mortandad, la riqueza fue redistribuida por las herencias y surgió un nuevo grupo de gente con dinero (los nuevos burgueses). Esto originó el fin de la sociedad feudal. La misma escasez de mano de obra provocó un interés por la técnica y por la ingeniería para reemplazar a los trabajadores fallecidos. Fue un proceso acelerado y progresivo porque la peste tuvo varios brotes durante sesenta años. Lo anterior impulsó el invento de máquinas y facilitó el surgimiento del Renacimiento, en el cual hubo un inusitado desarrollo de las artes, la política, la filosofía y las ciencias, y la ideal medioeval del teocentrismo fue sustituida por el antropocentrismo ${ }^{(14-16)}$.

\section{LOS VIRUS COMO CONQUISTADORES}

En 1492, a raíz del descubrimiento de "las indias", las infecciones, o, más concretamente, las epidemias, ocasionaron en Mesoamérica más muertos que los arcabuces, las espadas y los caballos de los conquistadores: llegaron la sífilis, el sarampión, la viruela, fiebre tifoidea, tifo, cólera, etc. Fue un verdadero genocidio biológico que afectó a nuestros ancestros. Esto está documentado en el sesudo libro de Jared Diamond, Guns, Germens and Steel ${ }^{(17)}$.

También las guerras propagaron epidemias, entre otras, la peste de Milán durante la Guerra de los Treinta años, en el siglo XVII, que se expandió por casi toda Europa. Mencionemos también la peste, mal llamada española, posterior a la Primera Guerra Mundial, que fue otra pandemia que ocasionó más muertos que la misma Gran Guerra... hasta que el 31 de diciembre del 2019, China reporta una nueva epidemia con una propagación muy alta, virulencia no muy marcada, una relativa baja letalidad y variable según las y las edades. No es una "gripa fuerte" típica de los coronavirus ni tampoco una neumonía fuerte: es una nueva enfermedad severa en las personas susceptibles, y una enfermedad un tanto distinta de lo que se reportó inicialmente.

\section{EL PROBLEMA BIOLÓGICO DE LA COVID 19}

Al hacer autopsias - más en Italia que en China- se demostró que la patología de esta enfermedad era más trombosis y micro trombosis localizadas no solamente en el pulmón ${ }^{(18)}$.

La COVID-19, como se sabe, puede ser asintomática y manifestarse como un simple "resfrío" o gripa sin consecuencias mayores. Pero en algunos casos puede presentarse una desregulación del sistema inmune asociado con alteración endotelial. El COVID-19 es en realidad una endotelitis e incluso una sepsis de origen viral con respuestas paninflamatoria, inmune y protrombótica exageradas y con manifestaciones no tan específicas que pueden llegar, finalmente, a una falla multisistémica y la muerte. Esto ha sido llamado "tormenta de citoquinas", debido a la sobreexpresión de estas polimorfas y complejas moléculas que desencadenan un incremento inusitado de estas, y no en forma localizada, sino sistémica ${ }^{\left({ }^{(19}\right)}$. Las más relevantes son IL-2, IL-6, IL-7, el factor estimulante de colonias de granulocitos del C-X-C quimiocina 10e (CXCL10), de la quimiocina (C-C motif), del ligando 2 (CCL2) y del factor de necrosis tumoral-alfa (TNFa) e interferón C, además de la ferritina, que agrava, tempranamente, la oxigenación tisular y celular (20-22).

Algunas de estas citoquinas están involucradas también con la enfermedad hipertensiva, de ahí que la hipertensión arterial (HTA) no tratada o no controlada, como comorbilidad, sea un marcador de mortalidad elevada en enfermos de COVID-19. La linfopenia es un hallazgo frecuente y precoz. Recientemente, se ha demostrado que existe alguna correlación entre la HTA y los linfocitos ${ }^{(23)}$ : en los hipertensos no controlados, las citoquinas proinflamatorias están elevadas y hay linfopenia; es decir, es evidente que existe una coincidencia entre la respuesta inflamatoria del COVID-19 con la enfermedad hipertensiva (que tiene un comportamiento inflamatorio a nivel vascular, e incluye rigidez arterial, envejecimiento vascular y alteraciones biomecánicas) (24).

Por lo anterior, no es sorprendente que la diabetes mellitus tipo 2 (DM2) sea también una comorbilidad de alto impacto para desenlaces más serios. La DM2 es una enfermedad asociada a un estado inflamatorio-oxidativo con disfunción endotelial precoz y acelerada y que genera memoria metabólica a nivel mitocondrial ${ }^{25}$. Sucede lo mismo con la falla cardíaca (inflamación vascular, rigidez arterial y oxidación) y en la obesidad, en la cual el adipocito es un magnificador de la angiotensina II (Ag II), con una consecuente propensión y facilitación a la inflamación y oxidación (26).

Hubo una controversia inicial por la confusión acerca de que los inhibidores del sistema renina-angiotensina (ISRA) podrían magnificar el daño o el riesgo del COVID-19 al expresar el receptor ECA-2 (la puerta de entrada del virus) (27) si se emplean los antihipertensivos tipo IECA (inhibidores de la enzima convertidora de angiotensina) o BRA (bloqueadores del receptor de la angiotensina II) en el tratamiento. La ECA-2 es un contrarregulador de la Ag II, la convierte en Ag 1-7, la cual, a través de su acción sobre los receptores Mas, genera una respuesta totalmente antagónica a la "mala" angiotensina II, puede neutralizar su efecto inflamatorio y estimular la producción del óxido nítrico (NO) con todas sus bondades vasculares conocidas 
Hablando de pandemias y pared vascular. Desde el endotelio hacia lo

socioeconómico-psicológico: una aproximación con evidencia

(antinflamatorias, antiproliferativas, antifibróticas, antioxidantes, antitrombóticas, profibrinolíticas, antiaterogénicas, etc.).

El SARS-CoV-2 se liga al receptor con la ayuda del ADAM17 (28) (proteína transmembrana disintegrina y metaloproteasa, la cual es activada por la proteína viral S) e ingresa en la célula. Una vez dentro, disocia la ECA2 la elimina de la superficie celular y permite así que la Ag II produzca una alteración sin un elemento que la contrarregule. Es aquí cuando se inicia el verdadero daño.

Para empeorar el cuadro, la reducción de la ECA2 pulmonar activa el receptor B1 de bradiquinina (BKDR1R) y genera una inflamación y daño vascular pulmonar mayores. Esto demuestra la interrelación entre el sistema kinin-calicreína (KKS, del inglés Kallikrein Kinin System) y el sistema renina-angiotensina (SRA) ${ }^{(29)}$.

Por otra parte, estudios epidemiológicos han demostrado que los enfermos hipertensos que toman ISRA (IECA, BRA) tienen menor incidencia de neumonía adquirida en la comunidad, lo cual desmitifica el riesgo del uso de estos

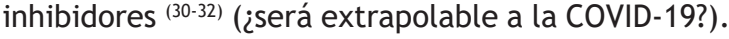

\section{El papel de la ECA-2 ante el SARS-CoV-2}

Cuando la ECA2 es disociada por la proteasa ligada a la membrana (el ADAM17), se produce la liberación de ACE2 soluble en el torrente sanguíneo, la cual parece tener efectos favorables sobre la función pulmonar en modelos de SARS, influenza e infección por el virus respiratorio sincitial (30). Los ISRA no inhiben la ECA2, pero hubo mucha información en la prensa científica sobre si estos ISRA podrían aumentar la susceptibilidad a la infección al aumentar la expresión de la ECA2, o si magnificarían las complicaciones.

Además, el SRA también está vinculado al sistema de péptidos natriuréticos, otro sistema contrarregulador que estimula la diuresis, la natriuresis y la vasodilatación. Los péptidos natriuréticos son inactivados por la neprilisina (endopeptidasa neutral o NEP), cuya inhibición por sacubutril logra activar la vía MasR mediante la generación de Ang 1-7 a partir de la Ang II. Es lo que conocemos hoy como ARNI (inhibidores de la neprilisina del receptor de angiotensina). Actualmente, la evidencia ha demostrado que el sacubutril, en combinación con un bloqueador del receptor de angiotensina, ha logrado un punto de inflexión para el manejo de la falla cardíaca con función de eyección disminuida, incluso este hecho está incorporado por las diferentes Guías para el manejo de la falla cardiaca (2017) ACC/AHA.ACCF (Guidelines for the Managment of Heart Failure. Circ 2017 136,6-10.). A la luz de la evidencia actual es todo lo contrario: el suspender los ISRA empeora el pronóstico de la COVID-19 (33).
La ACE2 se expresa en el pulmón y varios otros tejidos como cerebro, riñón, tracto gastrointestinal, tejido adiposo, testículos, cardiomiocitos y los vasos sanguíneos (células endoteliales y células musculares lisas vasculares). Es decir, involucra la pared vascular y su templo: el endotelio ${ }^{(19)}$.

Este daño endotelial por la COVID-19 y su respuesta inflamatoria pueden, además, desestabilizar las placas ateroscleróticas vulnerables, inducir inflamación y/o toxicidad cardíaca y activación de la cascada de coagulación, llevando a un estado de hipercoagulación que, al final, conduce a una coagulación intravascular diseminada ${ }^{(34,35)}$. En las autopsias se documentó que la COVID-19 no era una "simple neumonía viral", como ya fue mencionado. Existe un compromiso multisistémico que parte del daño endotelial y vascular con un componente microtrombótico inicial (enfermos con hipoxemia pero todavía asintomáticos), alteración posterior de la angiogénesis y apoptosis, seguidos de expresión de biomarcadores de lesión cardíaca, de depresión de la función ventricular, arritmias, elevación de troponinas, etc. ${ }^{(29)}$, y empeoradas por cloroquina, hidroxicloroquina, azitromicina y demás fármacos que prolongan el intervalo QT del electrocardiograma de superficie, hecho ya conocido (35). Es decir, cardiotoxicidad directa que se ha demostrado mediante resonancia magnética y ecocardiografía e incluso se ha documentado un cuadro de cardiomiopatía por estrés cardíaco agudo (síndrome de Takotsubo) ${ }^{(36)}$.

Por otro lado, la inmovilización prolongada, aunada a la disfunción endotelial, inflamación y estado protrombótico facilitan la trombosis venosa profunda y/o embolia pulmonar demostradas clínicamente como consecuencia del aumento del dímero $\mathrm{D}$ y del fibrinógeno. Un enfermo con los biomarcadores anteriores elevados más troponinas engloban una población de alto riesgo ${ }^{(37)}$.

En resumen, en el sistema cardiovascular, la COVID-19 puede generar miocarditis, falla cardíaca, infartos, arritmias, tromboembolismo pulmonar falla multisistémica y muerte, a partir de la disfunción endotelial inducida por el virus.

\section{¿CÓMO EXPLICAR MORTALIDAD EN ENFERMOS DE EDAD MEDIANA?}

Ante la evidencia que también gente joven ha fallecido sin comorbilidades aparentes, cabe la posibilidad de que la explicación sea la disfunción endotelial en la etapa subclínica. Es posible que, además de los biomarcadores y los exámenes de imágenes, evaluar la función endotelial o detectar precozmente su alteración sin métodos invasivos, sea una manera de pronosticar el riesgo de complicaciones en jóvenes con COVID-19. Este es un tópico que deberá tenerse en cuenta. El tiempo lo dirá. 


\section{COVID-19 ES UNA ENFERMEDAD DE ESTADIOS}

La COVID-19, como cualquier enfermedad infecciosa, comienza con la exposición e invasión dependientes, en este caso, de la carga viral aunada al tiempo de exposición, estado inmunológico previo y comorbilidades ya mencionadas.

Según datos de la OMS, cambiantes por las actualizaciones casi diarias, la COVID-19 tiene diferentes estadios (https://www.un.org/en/coronavirus).

La primera etapa (I) es similar al "flu" que, en alrededor de un $40 \%$, pude pasar desapercibida, y hasta un $80 \%$ puede aún permanecer así y ser manejado sintomáticamente en casa. La etapa II o neumonía leve también puede ser oligosintomática y presentar disnea leve, tos seca (debido a traqueítis) y desaturación asintomática (como una de las respuestas biológicas a la disminución de la ferritina y/o microtrombosis) por alteración en la captación y distribución de oxígeno. Corresponde a un 10-15 \% de los casos. Además, puede haber disgeusia, anosmia y/o diarrea. En el estadio III se presenta una neumonía grave con disnea marcada, fiebre, tos, etc. Es en esta etapa cuando el enfermo usualmente es hospitalizado (10\%). El estadio IV se caracteriza porque de 10 a $15 \%$ de los pacientes hospitalizados desarrollará el síndrome de dificultad respiratoria agudo (SDRA). En el estadio V, entre 2 a $20 \%$ de los enfermos desarrollarán las complicaciones cardiovasculares y sistémicas mencionadas, y que pueden agravarse por el desbalance iónico (hipocalemia, hipomagnesemia) o por el desequilibrio ácido-básico ${ }^{(38)}$.

El estadio VI corresponde a la etapa crítica de la infección: de diez pacientes intubados, solo se salvarán dos. El daño pulmonar inflamatorio y trombótico o microtrombótico es tan severo, que el brindar volumen y presión a un pulmón microtrombosado puede tornarse deletéreo. La solución o la cura no está en los ventiladores, son solo una estrategia coadyuvante, pero no definitiva $(39,40)$. Hasta la fecha $(13$ de diciembre de 2020), en esta etapa la única terapia farmacológica que ha mostrado evidencia de beneficio son los corticoides (específicamente, dexametasona), y solo en esta etapa de la enfermedad ${ }^{(41)}$. La cloroquina-hidroxicloroquina que se consideraba como una solución, no ha demostrado serlo, con base en la evidencia existente. Estos fármacos, que fueron promocionados hasta por dirigentes políticos, no son benéficos, ni como profilácticos ni en el tratamiento de la enfermedad.

Es necesario anotar que la mortalidad varía entre los países, o bien por diferencias étnicas o genéticas (incluso por el grupo sanguíneo, se sabe que las personas con grupo 0 tienen mejor pronóstico) ${ }^{(42)}$ o simplemente por indisciplina social o falta de uniformidad en la recolección y procesamiento de datos (por ejemplo, las personas que mueren en la casa por miedo a acudir oportunamente a un hospital "porque me pegan el virus", o los fallecidos en lugares de confinamiento es decir, ancianatos, cárceles e incluso en la calle (como sucedió en Guayaquil y otros lugares de Italia) o por subregistros, porque no se dispone de pruebas diagnósticas suficientes y por los resultados de exámenes falso positivos o falso negativos.

\section{¿Y LA INMUNIDAD?}

En muchos países son desconcertantes los informes acerca de una inmunidad "parcial" y no definitiva. Se ha reportado reinfecciones, aparentemente menos letales, y la inmunidad "de rebaño" parece no funcionar tan bien como en el caso de Suecia. Entonces, la última esperanza es la vacuna, que aunque se han acortado los procesos de ensayo terapéutico, algunos han tenido que ser replanteados. Aún no sabemos cuál será la vacuna (entre los cuatro tipos diferentes, por ahora en fase III de estudio). En algunos se requiere de revacunación, y aun no sabemos cuándo estarán disponibles para su uso masivo, ojalá que con equidad para todos los pueblos y países.

En un estudio específico reciente (13 octubre de 2020) para cuantificar la inmunidad para la COVID-19 se muestra que la inmunidad post-COVID-19 es de 5 a 7 meses. Pude recurrir ${ }^{(43)}$

\section{¿VOLVEREMOS A LA "NORMALIDAD" O EL MUNDO CAMBIARÁ?}

Ojalá no volvamos a la normalidad de la inequidad, marginamiento, egoísmos-egolatría, envidias, odios, violencia intra y extrafamiliar, corrupción endémica, polarizaciones pasionales, masacres, guerras, más inventos o armamentos nucleares en busca de la autodestrucción, ni el cierre de fronteras, ni el populismo barato por apetitos políticos, depredación, deforestación, polución... y demás hechos históricos. En la historia universal, la especie humana (mal llamada "La reina de la naturaleza") ha demostrado indolencia, por ejemplo: después de las dos guerras mundiales y la bomba atómica, vino la "Guerra Fría" con más conflictos bélicos (Corea, Vietnam, Afganistán, Siria, Guerra del Golfo, Guerra de los Seis Días, Ruanda, Chechenia, etc. ). Además, hoy la humanidad está armada nuclearmente más que nunca (dependemos de algún mandatario insensato que oprima un botón). Seguimos deforestando y generando una enorme polución, cuyas consecuencias han ocasionado el cambio climático y un mayor daño vascular por polución-oxidación. La economía es cada vez de mayor inequidad y la migración que, anteriormente, iba de oriente hacia occidente, ahora predomina de sur a norte. La desnutrición infantil, la muerte por hambre y, en el otro extremo, la obesidad con sus consecuencias cardio-metabólicas como muestra fiel 
Hablando de pandemias y pared vascular. Desde el endotelio hacia lo

socioeconómico-psicológico: una aproximación con evidencia

de un mundo desde siempre propenso hacia la inequidad y desigualdad social y económica. Todo esto nos ha mostrado que, ante las tragedias planetarias, a diferencia de otras especies animales, no nos unimos, no nos volvemos gregarios. Seguimos indiferentes ante los demás. Una pandemia de no muy alta letalidad (muchísimo menor comparada con la desnutrición, pobreza, enfermedades cardiovasculares, cáncer, etc.), pero que nos amenaza a todos sin distingos sociales ni regionales, nos ha generado una carga de miedo con sus implicaciones físicas, emocionales y económicas.

En la realidad y en la práctica, una estructura ultramicroscópica ha cambiado nuestra rutina y la "normalidad" y nos plantea una resignificación de las pequeñas cosas. En la teoría, sería esperanzador que, del asteroide B612, volviese El Principito de Antoine de Saint-Exupery a comentarnos, amablemente, sobre la forma tan extraña como los adultos vemos la vida. Pero nuestra estulticia y la condición humana de la que tanto habló Anna Arendt, no nos dejan vislumbrar un volver a lo "normal". Volveremos, seguramente, a vivir de una manera diferente conviviendo con un virus más en la Tierra, hasta que la ciencia (ahora ponderada, aplaudida y esperanzadora) logre contenerlo.

Y el tsunami post-COVID-19 disparará aún más la pobreza, la inequidad: habrá más miseria, menos empleos, más violencia para simplemente subsistir... y mucho más, y ya no seremos los "mismos de entonces". Se ha hablado mucho de resiliencia y de autoinventarnos. La realidad es que la resiliencia es un término físico adoptado por la psicología (estado en que, por ejemplo, una pelota de caucho que choca contra un muro adopta el golpe, pero vuelve a su estado inicial). Ahora tendremos que hablar y adaptarnos o crear la "nueva normalidad" y reinventarnos, no es posible. El ser humano, de acuerdo con Ortega y Gasset, es fruto, en gran parte, del "yo y mis circunstancias". Y si estas cambiaron abruptamente, deberemos seguir protegiéndonos: tapabocas por tiempo indefinido, distanciamiento social, ojalá no familiar, y razonables medidas de higiene. Y el segundo tsunami, más cercano, será la avalancha de enfermos con falla cardíaca descompensada, hipertensión arterial descompensada, diabéticos descompensados, etc., fruto del miedo de no consultar a hospitales por temor al virus o, simplemente, porque no tuvieron dinero para comprar sus medicamentos.

\section{¿Y EL PAPEL DE LA MEDICINA?}

En los últimos meses se han multiplicado los estudios sobre tratamientos posibles contra la COVID-19, aunque también se han difundido alertas sobre posibles fracasos o efectos adversos. El portal clinicaltrials.gov lleva el registro de los ensayos clínicos. Al momento de redactar este artículo había 2977 estudios en curso. Algunos medicamentos parecen prometedores y la eficacia de otros todavía está por probar, pero aún no tenemos la solución, solo tenemos paliativos.

Actualmente, en todo el mundo hay cerca de 200 investigaciones de fármacos para combatir el SARS-CoV-2, la mayoría de ellos son antivirales, aunque también se estudian otros que actúan en el sistema inmune. Además, se analiza el uso de anticuerpos monoclonales, de sueros de pacientes recuperados y hasta cocktails de terapias.

En la actualidad existe un gran estudio en marcha, el proyecto Solidaridad de la Organización Mundial de la Salud, en el que colaboran más de 90 países de todo el planeta. Otra iniciativa destacada es Recovery Trial, organizado por la Universidad de Oxford, en la que se analizan casos de más de 5000 pacientes. En España, el Instituto de Salud Carlos III lleva la cuenta de más de un centenar de proyectos de investigación destinados a frenar la COVID-19, y la página web de la Agencia Española de Medicamentos y Productos Sanitarios (AEMPS) recoge las recomendaciones médicas sobre los distintos fármacos disponibles, entre ellos, los más utilizados son remdesivir, lopinavir/ritonavir (LPV/R), cloroquina/hidroxicloroquina, tocilizumab (TCZ), sarilumab, ruxolitinib (RXT), siltuximab (STX), baricitinib (BAR), anakinra (ANK), interferón beta1b (IFN-B) e interferón alfa-2b (IFN-a2b).

\section{CONCLUSIONES}

Mientras no tengamos la vacuna para un virus mutable, no habrá un elemento curativo que erradique el SARS-CoV- 2 . Probablemente, como para la influenza, requeriremos revacunaciones, más los rebrotes por inmunidad no permanente, como ya fue mencionado (por ejemplo, en España, Alemania, Reino Unido, EE. UU. y China, entre otros). Habrá nuevos y muy costosos productos biológicos que generarán una brecha social entre quienes puedan adquirir la vacuna (que parece ya adelantada en Oxford, EE. UU., China y Rusia) o la biotecnología para fabricarla. Lamentablemente, será una medicina elitista, discriminatoria, selectiva y que ocasionará un gran problema de bioética. Los inventores ¿serán capaces de lograr la cura o los tratamientos que sean accesibles a los más de 6000 millones de pobladores de esta bolita azul que es nuestra casa?

Estamos ante algo desconocido. El dolor es ineludible, pero el sufrimiento es opcional.

Mientras tanto, aceptemos el ahora y vivámoslo plenamente. El presente es un regalo que jamás se repetirá. El pasado ya es historia. El futuro es incertidumbre. Ojalá el SARS-CoV-2 nos sirva para conocernos o para redescubrirnos a nosotros mismos, compartir el entorno de la familia y pensar, al fin, que todos somos simplemente terrícolas y no acaparadores de bienes o riquezas. 
Es mejor ver la verdad desnuda y no la mentira disfrazada.

Fuentes de financiamiento: Este artículo ha sido financiado por el autor.

Conflicto de interés: El autor declara no tener ningún conflicto de interés.

\section{REFERENCIAS BIBLIOGRÁFICAS}

1. Zhou P, Yang X-L, Wang X-G, Hu B, Zhang L, Zhang W, et al. A pneumonia outbreak associated with a new coronavirus of probable bat origin. Nature. 2020; 579: 270-3.

2. Bogoch II, Watts A, Thomas-Bachli A, Huber C, Kraemer MUG, Khan K. Pneumonia of unknown aetiology in Wuhan, China: potential for international spread via commercial air travel. J Travel Med. 2020; 27(2): taaa008.

3. Lu H, Stratton CW, Tang YW. Outbreak of pneumonia of unknown etiology in Wuhan, China: The mystery and the miracle. J Med Virol. 2020; 92(4): 401-2.

4. Cheng VCC, Lau SKP, Woo PCY, Yuen KY. Severe acute respiratory syndrome coronavirus as an agent of emerging and reemerging infection. Clin Microbiol Rev. 2007; 20(4): 660-94.

5. Rothan HA, Byrareddy SN. The epidemiology and pathogenesis of coronavirus disease (COVID-19) outbreak. J Autoimmun. 2020; 109: 102433.

6. Wang W, Tang J, Wei F. Updated understanding of the outbreak of 2019 novel coronavirus (2019-nCoV) in Wuhan, China. J Med Virol. 2020; 92(4): 441-7.

7. Holshue ML, DeBolt C, Lindquist S, Lofy KH, Wiesman J, Bruce H, et al. First case of 2019 Novel coronavirus in the United States. N Engl J Med. 2020; 382(10): 929-36.

8. Provenzano E. Coronavirus: Que sait-on du cas détecté à Bordeauz? [Internet]. Francia; 2020. Disponible en: https://www.20minutes. $\mathrm{fr} /$ bordeaux/2703783-20200126-coronavirus-sait-cas-detectebordeaux.

9. Folha de Sao Paulo. Brasil confirma primeiro caso do novo coronavírus [Internet]. Brasil; 2020. Disponible en: https://www1.folha.uol. com.br/equilibrioesaude/2020/02/brasil-confirma-primeiro-casodo-novo-coronavirus.shtml.

10. Huang C, Wang Y, Li X, Ren L, Zhao J, Hu Y, et al. Clinical features of patients infected with 2019 novel coronavirus in Wuhan, China. Lancet. 2020; 395(10223): 497-506.

11. Velavan TP, Meyer CG. The COVID-19 epidemic. Trop Med Int Health. 2020; 25(3): 278-80.

12. Cui J, Li F, Shi ZL. Origin and evolution of pathogenic coronaviruses. Nat Rev Microbiol. 2019; 17(3): 181-92.

13. Monto AS. Medical Reviews. Coronaviruses. Yale J Biol Med. 1974; 47(4): 234-51.

14. Ole J. La Peste Negra, 1346-1353. La historia completa. Editorial Akal: Madrid; 2011.

15.- López MM, Cardona Zorrilla AF. Rastros visibles del enemigo invisible: las epidemias en la historia. Rev Medicina. 2020; 42(2): 152-67.

16. Jácome Roca A. Las Pandemias de la Historia. Rev Medicina. 2020; 42(2): 140-2.

17. Diamond J. Guns, Germens y Steel. Penguim Random House Grupo Editorial: Madrid; 2007.

18. Carsana L, Sonzogni A, Nasr A, Rossi RS, Pellegrinelli A, Zerbi P, et al. Pulmonary post-mortem findings in a large series of COVID-19 cases from Northern Italy. MedRxiv. 2020.

19. Melgarejo E. COVID-19: extraño nuevo virus, endotelio y enseñanzas de una pandemia. Acta Méd Colomb. 2020; 45(3): 111-4.
20. Wong CK, Lam CWK, Wu AKL, Ip WK, Lee NLS, Chan IHS, et al. Plasma inflammatory cytokines and chemokines in severe acute respiratory syndrome. Clin Exp Immunol. 2004; 136(1): 95-103.

21. Klok FA, Kruip MJHA, van der Meer NJM, Arbous MS, Gommers DAMPJ, Kant KM, et al. Incidence of thrombotic complications in critically ill ICU patients with COVID-19. Thromb Res. 2020; 191: 145-7.

22. Zhou F, Yu T, Du R, Fan G, Lui Y, Liu Z. Factors for mortality of adult inpatients with COVID-19 in Wuhan, China: a retrospective cohort study. Lancet. 2020; 395: 1054-62.

23. Loperena R, Van Beusecum JP, Itani HA, Engel N, Larougmanie F, Xiao $L$, et al. Hypertension and increased endothelial mechanical stretch promote monocyte differentiation and activation: roles of STAT3, interleukin 6 and hydrogen peroxide. Cardiovasc Res. 2018; 114(11): 1547-63.

24. Mitchell GF, Guo C-Y, Benjamin EJ, Larson MG, Keyes MJ, Vita JA, et al. Cross-sectional correlates of increased aortic stiffness in the community: the Framingham Heart Study. Circulation. 2007; 115(20): 2628-36.

25. Avogrp A, Albiero M, Mangazzo L. Diabetes Mellitus: an inflamatory state. Care. 2011; 34(Suppl. 2): S285-90.

26. Ellulu MS, Patimah I, Khaza'ai H, Rahmat A, Abed Y. Obesity and inflammation: the linking mechanism and the complications. Arch Med Sci. 2017; 13(4): 851-63.

27. Hoffmann M, Kleine-Weber $H$, Schroeder $S$, Krüger $N$, Herrler T, Erichsen S, et al. SARS-CoV-2 cell entry depends on ACE2 and TMPRSS2 and is blocked by a clinically proven protease inhibitor. Cell. 2020; 181(2): 271-80.

28. Zunke F, Rose-John S. The shedding protease ADAM17: Physiology and pathophysiology. Biochim Biophys Acta Mol Cell Res. 2017; 1864(11 Pt B): 2059-70.

29. Zheng Y-Y, Ma Y-T, Zhang J-Y, Xie X. COVID-19 and the cardiovascular system. Nat Rev Cardiol. 2020; 17(5): 259-60.

30. National Institutes of Health $(\mathrm{NIH})$. Coronavirus disease 2019 (COVID-19) treatment Guidelines [Internet]. Bethesda; 2020. Disponible en: https: / /www.covid19treatmentguidelines.nih.gov/

31. Kreutz R, El-Hady Algharably EA, Azizi M, Dobrowolski P, Guzik T, Januszewicz $A$, et al. Hypertension, the renin-angiotensin system, and the risk of lower respiratory tract infections and lung injury: implications for COVID-19. Cardiovasc Res. 2020; 116(10): 1688-99.

32. Wu A, Good C, Downs JR, Fine MJ, Pugh MJ, Anzueto A, et al. The association of cardioprotective medications with pneumonia-related outcomes. 2014; 9(1): e85797.

33. Zhang P, Zhu L, Cai J, Lei F, Qin J-J, Xie J, et al. Association of inpatient use of angiotensin Converting Enzyme Inhibitors and Angiotensin II receptor blockers with mortality among patients with hypertension hospitalized with COVID-19. Circ Res. 2020; 126(12): 1671-81.

34. Levi M, Van der Poll T, Büller HR. Bidirectional relation between inflammation and coagulation. Circulation. 2004; 109(22): 2698-704.

35. Chatre C, Roubille F, Vernhet H, Jorgensen C, Pers Y-M. Cardiac complications attributed to chloroquine and hydroxychloroquine: a systematic review of the literature. Drug Saf. 2018; 41(10): 919-31.

36. Sala S, Peretto G, Gramegna M, Palmisano A, Villatore A, Vignale D, et al. Acute myocarditis presenting as a reverse TakoTsubo syndrome in a patient with SARS-CoV-2 respiratory infection. Eur Heart J. 2020; 41(19): 1861-2.

37. Ruan Q, Yang K, Wang W, Jiang L, Song J. Clinical predictors of mortality due to COVID-19 based on an analysis of data of 150 patients from Wuhan, China. Intensive Care Med. 2020; 46(5): 846-8.

38. Chen D, Li X, Song Q, Hu C, Su F, Dai J, et al. Hypokalemia and clinical implications in patients with coronavirus disease 2019 (COVID-19). MeRxiv. 2020.

39. Marini JJ, Rocco PRM, Gattinoni L. Static and dynamic contributors 
Hablando de pandemias y pared vascular. Desde el endotelio hacia lo socioeconómico-psicológico: una aproximación con evidencia

to ventilator-induced lung injury in clinical practice. pressure, energy, and power. Am J Respir Crit Care Med. 2020; 201 (7): 767-74.

40. Patel BK, Kress JP, Hall JB. Alternatives to invasive ventilation in the COVID-19 pandemic. JAMA. 2020; 324(1): 43-4.

41. World Health Organization. Corticosteroids for COVID-19: living guidance, 2 september 2020 [Internet]. Disponible en: https: / /apps. who.int/iris/handle/10665/334125

42. Ellinghaus D, Degenhardt F, Bujanda L, Buti M, Albillos A, Invernizzi $P$, et al. The ABO blood group locus and a chromosome 3 gene cluster associate with SARS-CoV-2 respiratory failure in an Italian-Spanish genome-wide association analysis. medRxiv. 2020.

43. Rippenger TJ, Uhrlaub JL, Watanabe M, Wong R, Castaneda $Y$, Pizzato HA, et al. Orthogonal SARS-CoV-2 serological assays enable surveillance of low prevalence communities and reveal durable humoral immunity. Immunity. 2020; 44-71.

\section{Correspondencia:}

Enrique Melgarejo R

Dirección: Av. 15 \# 122-35 Cons. 404. Bogotá, Colombia.

SA 110111.

Teléfono: 573208391750.

Correo electrónico: enrique.melgarejo@gmail.com

Recibido: 03 de enero de 2021

Evaluado: 18 de enero de 2021

Aprobado: 26 de enero de 2021

(c) La revista. Publicado por Universidad de San Martín de Porres, Perú.

(cc) Br Licencia de Creative Commons Artículo en acceso abierto bajo términos de Licencia Creative Commons Atribución 4.0 Internacional. (http://creativecommons.org/licenses/by/4.0/)

ORCID iDs

Enrique Melgarejo R C https://orcid.org/0000-0002-2667-1932 